\title{
EDITORIAL \\ Consequências do Contexto Atual Brasileiro para a Área da Saúde
}

\author{
Teresinha Heck Weiller
}

O atual cenário institucional brasileiro nos convida a refletir sobre os rumos, caminhos que estamos escolhendo enquanto sociedade para o campo da saúde, e as consequências na vida de cada brasileiro. O marco fundamental para pensarmos a saúde enquanto direito da cidadania se efetiva quando da promulgação da Constituição Federal de 1988, a chamada Constituição Cidadã, a qual reconhece que a "saúde é um direito fundamental do ser humano, devendo o Estado prover as condições indispensáveis ao seu pleno exercício". Assim, reconhecemos que a saúde é um direito público subjetivo, estendido a todos, o qual se efetiva a partir da instituição de políticas públicas no campo social e econômico que visam à redução dos riscos de doenças e de outros agravos. Esse conceito nos convida à reflexão de que a produção da saúde, do ponto de vista social, não é apenas uma atribuição do setor ou de profissionais do campo da saúde,

\footnotetext{
${ }^{1}$ Possui Graduação em Enfermagem e Obstetrícia pela Universidade Regional do Noroeste do Estado do Rio Grande do Sul (1983), Graduação em Direito pela Universidade Regional do Noroeste do Estado do Rio Grande do Sul (1995), Mestrado em Enfermagem em Saúde Pública pela Universidade de São Paulo (1998) e Doutorado em Enfermagem em Saúde Pública pela Universidade de São Paulo (2008). Atualmente é professora-adjunta da Universidade Federal de Santa Maria. Professora, Tutora de Campo e de Núcleo do Programa de Residência Multiprofissional Integrada em Sistemas Públicos de Saúde- Ênfase, Atenção Básica/ESF da UFSM. Professora do Programa de Pós-Graduação em Enfermagem-PPGENF/UFSM. Pró-Reitora de Extensão da Universidade Federal de Santa Maria (UFSM). Pesquisadora CNPq. teresinha.weiller@ufsm.br
}

mas está diretamente associada ao desenvolvimento social e econômico e à forma como, em cada momento da nossa história, compartilhamos a produção social. Por outro lado, compreendemos que a existência e manutenção do setor de saúde universal, integral e equitativo, desempenha papel importante para a garantia do acesso a serviços de saúde, os quais passam a contribuir para a redução das condições de adoecimento e sofrimento social. Destaco, no entanto, que a produção social da vida ultrapassa o setor saúde, estando diretamente ligada à existência de políticas públicas que contribuam para a existência da vida.

Nesse contexto, preocupa-me o cenário político atual que tem contribuído para agravar a crise econômica, retomando discursos já vividos pela sociedade brasileira, que busca justificar a "crise" pela necessidade de reposicionamento dos gastos públicos, entre eles a saúde, a educação e as políticas de inclusão social. Esse novo momento construído por diferentes interesses no campo da política pauta sua retórica na necessidade de redução das chamadas políticas sociais para "resolver" a crise. Qual crise? De projeto? Do capital?

Sabemos que em um país que ainda é profundamente marcado por diferenças sociais e econômicas essa "crise" vai agir de forma diferente nas camadas populacionais. Se compartilhamos do conceito de que a saúde é determinada socialmente, é nesse contexto que a ação 
social se materializa e no qual vivenciamos os conflitos e suas contradições. Neste cenário vamos identificar, a partir da compreensão da determinação social do processo saúde-doença a intrínseca relação entre as condições de vida e de trabalho dos indivíduos e dos coletivos, efetivadas nas esferas dos macrodeterminantes. Estes têm relação direta com as políticas que impactam no desenvolvimento do país. É de sua natureza a existência de contradições intensas e permanentes. Quando tomamos as ações específicas do campo da saúde estamos nos referindo às microdeterminantes. Sua presença ou ausência impacta na ampliação, manutenção ou controle das doenças crônicas. Diz respeito aos determinantes individuais ou de grupos que se referem à forma como os indivíduos/grupos vivem em sociedade, seus hábitos e estilos de vida, salientando que o modo de vida possibilita a ocorrência de doenças crônicas. Nessa perspectiva, a existência ou não de serviços de saúde impactam de forma perversa nos determinantes de desigualdades social, agravado nesse momento por uma "ideia" de que o Estado brasileiro não pode suportar os gastos com as políticas sociais. Assim sendo, caminhamos para o agravamento das condições objetivas de vida. Destaco que a produção de saúde tem relação direta com o acesso a alimentos, educação, saúde, assistência social, moradia, entre outros fatores. E parece que são exatamente essas dimensões não mais reconhecidas como importantes para a diminuição do fosso social em um país que ainda não atingiu os indicadores do primeiro mundo.

Nós que construímos diariamente o campo da saúde em nosso país estamos muito preocupados com o momento político. $\mathrm{O}$ cenário atual e as perspectivas futuras apontam para um financiamento decrescente do setor, comprometendo a universalização do atendimento. Convivemos em pleno século 21 com altas taxas de miséria, as quais atingem parcelas significativas de brasileiros. A crise econômica traz dentro de si o agravamento das condições objetivas de vida com o desemprego em massa, fragilida- des econômicas e sociais para o conjunto das famílias brasileiras, que acentuados pela transição demográfica e epidemiológica, aumentam a carga de danos na área da saúde.

Por fim, é necessário refletirmos sobre o momento que estamos vivendo no campo político. Mais do que se tratar de enfrentamentos de velhos problemas estruturais, tais como a corrupção, esta "crise" vem ao encontro de setores conservadores da sociedade brasileira que não aceitam ou não aceitaram que a nossa legislação tenha avançado no sentido de ampliação de diretos, de cidadania. A contradição permanente que se coloca para o campo da saúde sempre será o de ampliarmos o acesso. Como nos ensina Paulo Freire, a questão é e sempre será ideológica. Assim, a pergunta que fica é: Estamos nós do lado dos que defendem a inclusão ou não das camadas mais desfavorecidas da nossa sociedade? 